\title{
Review Article \\ RNAi and Antiviral Defense in the Honey Bee
}

\author{
Laura M. Brutscher ${ }^{1,2,3}$ and Michelle L. Flenniken ${ }^{1,2}$ \\ ${ }^{1}$ Department of Plant Sciences and Plant Pathology, Montana State University, Bozeman, MT 59717-3150, USA \\ ${ }^{2}$ Institute on Ecosystems, Montana State University, Bozeman, MT 59717-3490, USA \\ ${ }^{3}$ Department of Microbiology and Immunology, Montana State University, Bozeman, MT 59717-3460, USA
}

Correspondence should be addressed to Michelle L. Flenniken; michelle.flenniken@montana.edu

Received 15 July 2015; Revised 25 November 2015; Accepted 29 November 2015

Academic Editor: Peirong Jiao

Copyright (C) 2015 L. M. Brutscher and M. L. Flenniken. This is an open access article distributed under the Creative Commons Attribution License, which permits unrestricted use, distribution, and reproduction in any medium, provided the original work is properly cited.

\begin{abstract}
Honey bees play an important agricultural and ecological role as pollinators of numerous agricultural crops and other plant species. Therefore, investigating the factors associated with high annual losses of honey bee colonies in the US is an important and active area of research. Pathogen incidence and abundance correlate with Colony Collapse Disorder- (CCD-) affected colonies in the US and colony losses in the US and in some European countries. Honey bees are readily infected by single-stranded positive sense RNA viruses. Largely dependent on the host immune response, virus infections can either remain asymptomatic or result in deformities, paralysis, or death of adults or larvae. RNA interference (RNAi) is an important antiviral defense mechanism in insects, including honey bees. Herein, we review the role of RNAi in honey bee antiviral defense and highlight some parallels between insect and mammalian immune systems. A more thorough understanding of the role of pathogens on honey bee health and the immune mechanisms bees utilize to combat infectious agents may lead to the development of strategies that enhance honey bee health and result in the discovery of additional mechanisms of immunity in metazoans.
\end{abstract}

\section{Introduction}

Honey bees (Apis mellifera) contribute vital pollination services to agricultural crops and native landscapes, accounting for over $\$ 15$ billion/year in economic value in the US [1]. In addition, the honey bee is a model organism for epigenetic, behavioral, and host-pathogen interaction studies [2-10]. Since 2006, the US and parts of Europe have experienced high annual colony losses ( 33\% annual loss in the US) [9, 1113]. In the US, colony mortalities are partially attributed to Colony Collapse Disorder (CCD) [14-19]. These losses have stimulated greater interest in investigating honey bee biology, including the role of pathogens in colony mortalities and the role of the RNA interference (RNAi) mechanism in honey bee antiviral defense.

Pathogen incidence and abundance have been positively associated with CCD-affected colonies in the US [15, 19, 20] and colony losses in the US [21, 22], Canada [23], and European countries, including, Spain [24], Italy [25, 26], Belgium [27], and Germany [28]. In the US, Israeli acute paralysis virus (IAPV) was more abundant in colonies with less food stores and less developing bees/brood [29], and Lake Sinai viruses (LSV) 1 and 2 were more abundant in weak/less populated colonies from a small sample cohort [22]; however, this correlation was not seen in a larger sample cohort [30]. Honey bees are infected by a wide variety of pathogens (i.e., viruses, bacteria, microsporidia, and trypanosomatids) and also suffer from ectoparasitic mite (Varroa destructor) infestation (reviewed in [31]). The majority of honey bee pathogens are positive sense, singlestranded RNA viruses. The short-interfering RNA (siRNA) pathway of RNA interference (RNAi) is a major antiviral immune mechanism in solitary insects (reviewed in [32]) and is involved in honey bee antiviral defense.

RNAi is a post-transcriptional, sequence-specific, gene regulation mechanism conserved across several phyla, including plants, invertebrates, and mammals (reviewed in [33]). RNAi-mediated gene knockdown is a useful tool for assessing gene function in honey bees and other organisms for which additional reverse genetic tools are not available. 
While experimental introduction of virus sequence-specific dsRNA reduced honey bee virus infections in adults and larvae [29, 34-39], introduction of non-sequence-specific dsRNA also resulted in virus reduction and altered gene expression [38]. This is consistent with global changes in honey bee gene expression, including untargeted genes (i.e., off-target effects), observed from administration of dsRNA $[40,41]$. Together these results suggest that dsRNA not only serves as the substrate for RNAi-mediated gene regulation but also may function as a trigger of gene regulatory signal transduction cascades. Future studies aimed at determining the relative contribution of RNAi and other honey bee antiviral defense pathways will be important for the development of strategies that limit virus infection and for investigating immune gene function in bees. In this review, we discuss RNAi as a tool for gene knockdown in honey bees, the role of the siRNA pathway of RNAi in honey bee antiviral defense, and additional honey bee antiviral defense pathways, including evidence of a non-sequence-specific dsRNA-stimulated immune pathway in honey bees.

\section{RNA Silencing: Machinery and Functions}

RNA silencing is a mechanism of post-transcriptional gene regulation conserved across several phyla that encompasses three distinct pathways (reviewed in [32, 42]), including the short-interfering RNA (siRNA), microRNA (miRNA), and piwi-interacting RNA (piRNA) pathways. Each of these pathways is characterized by its unique biological function and involvement of distinct proteins. The siRNA pathway is involved in antiviral defense in plants and invertebrates, but its function in mammalian immunology is debated (reviewed in [43-45]). This pathway is triggered by cytosolic dsRNA produced by replicating viruses or introduced experimentally. Double-stranded RNA is recognized and cleaved by the RNAse III enzyme, Dicer (Dicer-2 in Drosophila [46, 47] and Dicer-like in Apis mellifera [48]), into 21-22 bp shortinterfering RNAs (siRNAs) (reviewed in [49]) (Figure 1). siRNAs are short dsRNAs with $5^{\prime}$ monophosphate ends and two nucleotide overhangs at their $3^{\prime}$ hydroxyl-termini (reviewed in [50]). The siRNAs are subsequently bound by Argonaute (AGO2), an endoribonuclease and catalytic component of the multiprotein RNA-induced silencing complex (RISC). One strand of the siRNA, the passenger strand, is then released, leaving the other strand, the guide strand, to target complementary viral and transposon sequences for cleavage (reviewed in [50]). miRNAs are derived from endogenous nuclear-encoded short-hairpin RNAs that are processed into shorter hairpin RNAs (pre-miRNA), cleaved by Dicer into 21-22 bp segments in the cytosol and incorporated into RISC (reviewed in [50]). The miRNA-containing RISC then targets complementary host-encoded mRNA transcripts for degradation or translational inhibition. Conversely, miRNAs can serve to induce transcription and translation of mRNA, reduce nonsense-mediated RNA decay, and improve mRNA stability (reviewed in [51]). miRNAs can function in antiviral response via targeting of viral nucleic acid and host gene regulation (reviewed in [51]). piRNAs, which are larger than siRNAs and miRNAs (24-32 nucleotides (nts)), are generated

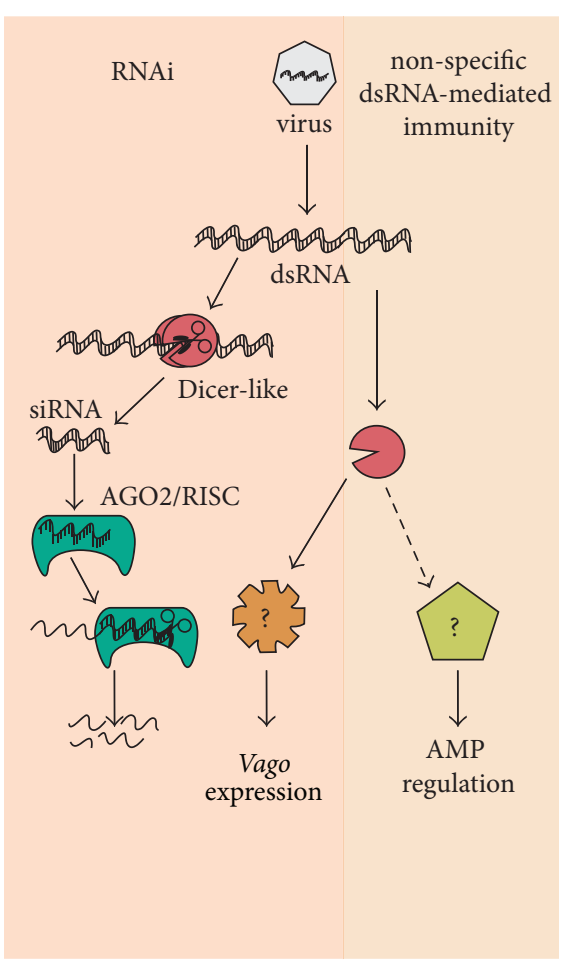

FIGURE 1: RNAi and non-sequence-specific dsRNA mediated antiviral defense in honey bees. The short-interfering RNA (siRNA) pathway of RNA interference (RNAi) is important for honey bee antiviral defense and experimental gene knockdown. Although not yet fully characterized, the honey bee RNAi-pathway is likely induced by Am Dicer-like cleavage of viral dsRNA into 21-22 bp siRNAs. Following cleavage, siRNA is bound by AGO2 (Argonaute-2), the catalytic subunit of the multiprotein RISC (RNA-induced silencing complex). The passenger strand is then released and the guide strand aids RISC in targeting and cleaving complementary viral genome sequences. In Drosophila melanogaster, Dicer-2 also acts as a dsRNA sensor which, when bound to dsRNA, initiates a signal transduction cascade that results in increased expression of Dm Vago and, in turn, increased expression of Jak-STAT pathway-associated genes. In honey bees, nonspecific dsRNA-mediated reduction in virus abundance [38] may involve Am Dicer-like and Am vago, but the mechanism(s) of this response have not been fully characterized. This figure is adapted from [10].

in a Dicer-independent manner from single-stranded RNA precursors transcribed from genomic regions (reviewed in $[49,52,53])$. piRNAs are involved in transposon silencing, epigenome regulation, and antiviral defense (reviewed in $[49,52,53])$. The focus of this review is on the use of the siRNA/RNAi pathway in experimental gene knockdown and its role in antiviral defense in honey bees. Further use of the term "RNAi" in this review is in regard to the siRNA pathway.

\section{RNAi-Mediated Knockdown of Endogenous Gene Expression}

RNAi is involved in antiviral defense and endogenous gene regulation. This mechanism can also be triggered experimentally to study gene function in organisms for which the tools for facile gene knockout are not available. RNAi-mediated 
gene knockdown has been used to study gene function in different honey bee developmental stages, including embryos [54-60], larvae [3, 56, 61-68], pupae [56, 69, 70], and fully developed adult honey bees [2, 4, 71-83] (reviewed in [84]). Importantly, these studies have demonstrated that the RNAi machinery is functional in honey bees.

The variable efficacy of RNAi-mediated gene knockdown observed in honey bees is likely gene-, dsRNA trigger-, and tissue-specific. The most effective use of RNAi-mediated gene knockdown in adult bees has been targeting of the hemolymph (insect blood) protein vitellogenin; vitellogenin expression was reduced at the mRNA (>75\%) and protein levels in several studies $[2,72-74,76,81]$. The efficacy of vitellogenin RNAi-mediated knockdown in honey bees is likely, in part, a consequence of its involvement in a positive regulatory feedback loop in which vitellogenin and juvenile hormone mutually suppress each other $[72,85]$. In short, bees with less vitellogenin produce less vitellogenin. RNAi-mediated knockdown of vitellogenin in several studies has provided evidence for its role in aging by acting as an antioxidant [73] and in the timing of foraging behavior [74, 76]. The high efficiency of RNAi-mediated knockdown of honey bee vitellogenin may be partially attributed to enhanced targeting of siRNAs and dsRNAs to the fat body where vitellogenin is produced [86]. Similarly, intra-abdominal injection of either dsRNA or siRNA targeted against the glycerol-3-phosphate dehydrogenase (amGPdh) gene significantly decreased amG$P d h$ transcripts in the fatty body (i.e., $>70 \%$ decrease), but not in the ovaries, flight muscles, or head [78]. For comparison, a study that aimed to silence octopamine receptor expression via injection of dsRNA into the antennae observed $\sim 40 \%$ decreased expression [71]. In addition, silencing of the hypopharyngeal amylase via dsRNA injection into the abdomen resulted in $\sim 30 \%$ decreased expression in the hypopharyngeal glands [87]. The fat body is the site for insect humoral immunity (e.g., antimicrobial peptide production) and is involved in many metabolic processes (reviewed in $[86,88])$. Therefore, gene knockdown studies in the fat body may be useful for studying honey bee metabolic and immune pathways.

\section{RNAi in Antiviral Defense}

The siRNA/RNAi is a major antiviral defense mechanism in solitary insects, including fruit flies and mosquitos (reviewed in [89]). The piwi-interacting RNA (piRNA) pathway has also been linked with antiviral response in insects via the detection of piRNA-sized viral RNAs in persistently infected Drosophila ovarian sheath cells and the discovery of pingpong dependent piRNAs in arbovirus-infected Aedes spp. (reviewed in $[49,90]$ ). miRNAs may have contrasting roles in insect-virus infection; virally derived miRNAs can disrupt host cell transcription and translation, but host miRNAs may be used to target and disrupt viral nucleic acid (reviewed in [51]). However, the roles of the miRNA and piRNA pathways in honey bee antiviral defense are not well characterized; thus, in this review, we focus on the siRNA pathway of RNAi.

The honey bee genome encodes the siRNA/RNAi machinery dicer-like, ago-2, and $r 2 d 2$ [48, 91], and bees are readily infected by positive sense, single-stranded RNA viruses (reviewed in [92]). These single-stranded RNA viruses generate double stranded RNA intermediates during their replication cycle and likely have significant secondary RNA structure within their genomes [92, 93], either of which may serve as Am Dicer-like substrates and trigger the honey bee siRNA pathway (Figure 1).

The role of RNAi in honey bee antiviral defense was first demonstrated when bees fed Israeli acute paralysis virus (IAPV) and IAPV-specific dsRNA had reduced IAPV levels as compared to bees fed only virus [34]. In addition, IAPVspecific siRNAs were detected by Northern blot analysis in the IAPV-specific dsRNA treated bees [34], indicating that the dsRNA and virus genomes were cleaved by Dicer-like and/or AGO2. IAPV replication was also decreased in bees fed siRNAs targeting the Internal Ribosomal Entry Site (IRES) of IAPV [39]. Similar results were obtained when larvae and adult bees fed dsRNA targeting Deformed wing virus (DWV) had reduced mortality, virus load, and deformed wing symptoms [37]. The effect of dsRNA administration on the outcome of virus infection was also examined in the Eastern honey bee, Apis ceranae [36]. In turn, there has been commercial/agricultural interest in utilizing RNAi-mediated antiviral treatments in honey bee colonies (reviewed in [35, $94,95])$. Initial field studies suggested that feeding honey bees IAPV-specific dsRNA resulted in increased honey production and larger colony size [35]; however, additional research is needed to confirm the mechanism of action and further investigate additional biological effects of dsRNA/siRNA treatments.

RNAi-mediated antiviral defense in naturally infected bees, which were not fed either dsRNA or siRNA triggers, was documented and characterized by sequencing small RNA libraries [96]. Small RNA sequence data indicated that bees from CCD-affected colonies had higher amounts of $22 \mathrm{nt}$ siRNAs spanning the genomes of IAPV, Kashmir bee virus (KBV), and Deformed wing virus (DWV) as compared to non-CCD colonies. Most of the IAPV-specific siRNAs were negative sense, indicating their role as guide strands that target RISC to viral genomes/mRNAs [96]. Moreover, DWV virus levels were broadly proportional to the abundance of DWV-specific siRNAs in both orally infected and mitevectored infections in developing bees [97]. Transcriptome (RNASeq) sequence data also indicated the role of the RNAi machinery in antiviral defense, as the expression of Argonaute-2 and Dicer-like were greater in bees experimentally infected with IAPV as compared to mock-infected controls [6]. Intriguingly, transcriptional level regulation of the Drosophila RNAi genes in response to virus infection has not yet been documented $[98,99]$, suggesting that regulation of antiviral defense mechanisms in honey bees and fruit flies may differ.

Like many insect-infecting viruses, some honey bee viruses have likely evolved specific mechanisms to counteract RNAi-mediated antiviral defense, including virus-encoded suppressors of RNAi (VSR). For example, the B2 protein dimer of Flock house virus binds dsRNA, subsequently preventing Dicer- 2 cleavage of long dsRNA $[100,101]$ and siRNA loading into RISC [101]. Dicistroviruses encode protein 1A, a 
VSR with differential modes of action (e.g., it binds to Dicer-2 or AGO2) and efficacy that varies by virus (reviewed in [90]). Based on analysis of VSR-expressing viruses (i.e., Drosophila $\mathrm{C}$ virus and Cricket paralysis virus), the presence of the highly conserved DvExNPGP motif and upstream coding sequences are indicative of the ability to express VSR proteins $[102,103]$. Sequence analysis revealed that the honey bee dicistroviruses $\mathrm{IAPV}$ and $\mathrm{KBV}$ and Acute bee paralysis virus (ABPV) contain a DvExNPGP motif at the $5^{\prime}$ terminus of their genomes, suggesting these honey bee-infecting viruses may encode a VSR [29]. Experimental feeding of naturally IAPV-infected bees with siRNAs targeting the putative IAPV-encoded RNAi suppressor decreased IAPV loads at least three times more than treatment with siRNAs targeting the IAPV IRES $[29,39]$. Better understanding of the importance of RNAi in honey bee antiviral defense and the means by which viruses may evade the honey bee antiviral response will facilitate the manipulation of these mechanisms in the lab as well as their potential application in the field setting.

The dsRNA uptake mechanisms in insects and their relationship to systemic RNAi and antiviral defense are not completely understood. Current studies suggest that there are at least two mechanisms of dsRNA uptake in insects: transmembrane channel-mediated uptake (reviewed in [104]) and endocytosis-mediated uptake [105-107]. SID1 (systemic RNA defective), a dsRNA-transporting transmembrane protein originally identified in C. elegans $[108$, 109], has been implicated in facilitating systemic RNAi in honey bees; bees injected with dsRNA had over three times greater expression of SID-1 than controls [110]. C. elegans also encodes additional SID proteins, SID-2, SID-3, and SID5 , which have also been implicated in dsRNA uptake but have not been identified in the honey bee genome [111-113]. Honey bees encode for one SID-1 ortholog with two protein isoforms (XP_006565236.1 and XP_006565237.1), which both share $\sim 25 \%$ amino acid identity with the C. elegans SID-1 (NP_504372.2) [114]. In addition, transgenic Drosophila S2 cells expressing the C. elegans SID-1 protein had improved dsRNA uptake [109]. Interestingly, SID-1 is not present in all insect genomes (reviewed in [104]), including Drosophila [115], and is not required for systemic RNAi in locusts [116]. Proteins involved in phagocytosis and endocytosis may function in dsRNA uptake, as the scavenger receptors SR-CI and Eater and the endocytosis-associated proteins clathrin heavy chain and H+ ATPase are important for dsRNA uptake in Drosophila S2 cells $[105,106]$. Investigating dsRNA uptake and systemic RNAi will be an important step towards further characterizing honey bee antiviral response.

Double-stranded RNA treatment of honey bees has also been employed to reduce gene expression in honey beeassociated parasites including the microsporidia Nosema ceranae [117] and the ectoparasitic mite Varroa destructor [118]. Honey bees inoculated with Nosema spores and fed dsRNA targeting Nosema-specific ADP/ATP genes had reduced Nosema spore count, and Nosema had lower expression of the targeted genes [117]. Likewise, when bees were fed dsRNA targeting mite sequence-specific housekeeping genes, mites had lower levels of the targeted transcripts [118]. Interestingly, long, unprocessed dsRNAs were detected in bee hemolymph three days after feeding dsRNA [118]. The biological relevance of dsRNA as a systemically active molecule in naturally infected honey bees is unknown, but it is remarkable that orally introduced dsRNA remains stable enough to spread throughout the honey bee host and into associated parasites $[117,118]$.

It is interesting that several studies have demonstrated that dsRNA/siRNA feeding is an effective strategy to reduce virus loads in both larval-stage and adult bees, while achieving effective in vivo gene silencing is difficult in mammalian model systems (reviewed in [119]). Tail-vein injections of siRNA in postnatal mice have been an effective strategy for gene knockdown [120], but overall systemic siRNA delivery into mammalian systems often requires siRNAs with chemical modifications such as lipophilic conjugates or nanoparticle mediated delivery (reviewed [119, 121]). Preliminary results on the effects of RNAi-mediated treatment of honey bee viruses and parasites are promising, but additional investigation is required to better understand the feasibility, effectiveness, and risk of off-target effects. Additionally, it will be important to develop methods to functionally test the role of the RNAi machinery via gene knockout/knockdown. Genome integration of IAPV also requires further examination [122]. Both genome-integrated RNA viral sequences, putatively encoding for target nucleic acid or reverse-transcriptase, and RNAi are involved in limiting and maintaining persistent virus infections in $D$. melanogaster $[42,107]$. These and other studies will reveal the role of RNAi in honey bee antiviral defense.

\section{Additional Antiviral Defense Mechanisms}

Multiple mechanisms are involved in insect immune responses, including phagocytosis, melanization, and signal transduction of the Toll, Imd (immune deficiency), and Jak/STAT (Janus kinase and Signal Transducer and Activator of Transcription) innate immune response pathways which result in the production of antimicrobial peptides (AMPs) and other effector proteins (reviewed in $[89,90,123]$ ). There are multiple orthologous proteins utilized by both insect and mammalian immune pathways (reviewed in $[124,125]$ ), including Toll-like receptors (TLRs). While mammalian TLRs recognize and bind specific pathogen associated molecular patterns, the D. melanogaster Toll acts downstream of pathogen recognition [90, 123]. Honey bees encode for all the major components of the Toll, Imd, JNK, Tor, and Jak-STAT pathways (except upd), AMPs (i.e., abaecin, hymenoptaecin, apidaecin, and defensin), and prophenoloxidases [126].

Transcriptional studies of virus-infected honey bees have implicated the Jak-Stat, Toll, and Imd pathways in antiviral defense (reviewed in [10]). For example, bees infected with DWV had greater expression of the Imd pathway member dorsal-1A [25], and bees fed IAPV had increased expression of Toll pathway members (i.e, toll-6, cactus, and the AMP hymenoptaecin) and Jak/STAT pathway members (i.e., $c b l$, stat, pias, and hopscotch) [29]. Nevertheless, not all infection studies investigating transcriptional responses to the same virus followed the same trends. In contrast to bees fed IAPV, 
bees from naturally infected IAPV colonies did not have differential regulation of Jak/STAT or Imd pathways [29]. These inconsistencies may be due to different experimental factors such as difference in virus isolate/strain utilized, infection route, age of bees, and tissue examined (reviewed in [10]). Further investigation of the role of these and other innate immune pathways in honey bee antiviral defense will lead to a better understanding of the mechanism(s) of honey bee antiviral defense and reveal unique honey bee host-virus interactions.

\section{Nonspecific dsRNA Triggered Virus Reduction}

In addition to inducing RNAi, dsRNA may also engage a previously uncharacterized non-sequence-specific immune pathway in honey bees [38] (Figure 1). Bees coinjected with Sindbis virus (SINV) and sequence-specific dsRNA or nonsequence-specific dsRNA had similarly decreased viral titers as compared to bees injected with virus only [38]. Likewise, adult bees treated with non-virus specific dsRNA (i.e., GFP(green fluorescent protein-) targeting) and infected with DWV had a greater rate of survival as compared to DWVinfected bees that received no dsRNA-treatment [37]. In addition, experimental introduction of nonspecific dsRNA alone in honey bees perturbs honey bee gene expression $[38,41]$. Transcriptome analysis of honey bee larvae fed GFP-targeting dsRNA revealed $\sim 1,400$ differentially regulated genes (DEGs) [41]. Nine genes had sequence similarity with $21 \mathrm{nt}$ regions of GFP, indicating off-target RNAi [41]. However, most DEGs did not share sequence similarity with dsRNA-GFP and were reported to function in oxidoreductase activity, aging, cell homeostasis, morphogenesis, response to external stimulus and stress, and immune response [41]. Also, bees injected with non-sequence-specific dsRNA had differential expression, including decreased expression of several apidaecin AMP family members [38]. In a recent study that examined the role of RNAi-mediated antiviral defense in bumblebees (i.e., Bombus terrestris), adults fed non-sequence-specific dsRNA had increased survival when infected with IAPV and similar virus titers as compared to bees fed dsRNA targeting IAPV [127]. Together these results suggest that honey bees and other members of the Apidae family may have an alternative dsRNA-stimulated immune pathway akin to the interferon response in mammals. Mammals have dsRNA recognition receptors such as Toll-like receptor 3 (TLR3), Protein kinase R (PKR), Retinoic acid-inducible gene 1 (RIG-I), and Melanomadifferentiationassociated gene 5 (MDA-5), that when activated, induce expression of numerous genes that contribute to an antiviral state (reviewed in [128]). Analogously, non-sequence-specific dsRNA-mediated immune pathways may be important for antiviral defense in honey bees.

Nonspecific dsRNA-triggered antiviral immunity has also been observed in other arthropods including Chinese oak silk moth pupae [129], shrimp [130-134], Bombyx mori larvae [135], and sandfly cells [136], implicating dsRNA as a viral pathogen associated molecular pattern (PAMP or VAMP). In addition, there is evidence that Dicer-2 serves as a pathogen recognition receptor (PRR) of dsRNA in both D. melanogaster [47] and Culex pipiens f. molestus mosquito cells [137]. When bound with dsRNA, Dicer2 stimulates a signal-transduction cascade that results in increased expression of vago and Jak-Stat pathway genes (reviewed in [90, 123]) (Figure 1). Intriguingly, larvae orally infected with DWV from Varroa infested colonies had significantly greater expression of the honey bee ortholog of vago as compared to control larvae from colonies with lower mite pressure [97]. Though administration of non-sequencespecific dsRNA does not always improve survival or reduce viral titer in virus infected bees $[34,36]$, it is important to further examine the mechanisms involved in non-sequencespecific dsRNA-mediated antiviral immunity in honey bees.

\section{Conclusion}

Honey bees are essential pollinators of agricultural crops and many plant species. Since 2006, annual losses of honey bee colonies in the US have been high (i.e., averaging 33\%). Pathogen incidence and abundance correlate with CCD, as well as colony health and loss in multiple studies. Continued investigation of honey bee host-pathogen interactions is important to better understand the role of pathogens in colony losses. Many positive sense single-stranded RNA viruses infect honey bees. Honey bee virus infections result in a range of outcomes, likely caused by varying immune responses due to genetic differences [138, 139], coinfection with additional pathogens $[20,31,140]$, adequate bee nutrition [141-143], the effect of the bee microbiome [144, 145], and/or exposure to environmental factors including agrochemicals and weather events [146-149]. The RNAi mechanism plays a role in honey bee antiviral defense but the relative contribution of this and other immune pathways has not been fully elucidated. The efficacy of RNAi-mediated treatment against honey bee viruses together with the fact that honey bee viruses encode for putative VSRs supports that RNAi is an important honey bee antiviral defense mechanism. In addition, several studies implicate the involvement of innate immune pathways (i.e., Jak-Stat, Toll, and Imd) and non-sequence-specific dsRNA-mediated immune responses in honey antiviral defense.

Honey bee gene knockout models are not yet available, so experimental induction of RNAi has become an important tool for studying gene function in honey bees. Although effective RNAi-mediated gene knockdown has been demonstrated in the fat body, gene knockdown in other tissue types (e.g., reproductive tissue [78]) remains a challenge. Further development of honey bee cell culture systems [150-153], and perhaps the use of the endoribonuclease CRISPR/Cas9mediated gene knockout system [154], will also facilitate future investigations of RNAi and innate immune pathways in honey bees. Continued investigation of honey bee hostpathogen interactions and better characterization of the honey bee immune system may result in implementation of strategies that benefit honey bee colony health and result in the discovery of additional evolutionarily conserved immune mechanisms. 


\section{Conflict of Interests}

The authors declare that there is no conflict of interests regarding the publication of this paper.

\section{Acknowledgments}

This work was supported in part by National Institutes of Health IDeA Program COBRE Grant GM110732, National Science Foundation EPSCoR NSF-IIA-1443108, Project Apis $m$., and the Montana State University Agricultural Experiment Station. The Flenniken laboratory is also supported by the Montana Department of Agriculture, the Montana State Beekeepers Association, Montana State University, and the United States Department of Agriculture National Institute of Food and Agriculture, Agriculture and Food Research Initiative (USDA-NIFA-AFRI) program. Laura M. Brutscher is supported by the Project Apis m.-Costco Honey Bee Biology Fellowship. The authors would like to thank members of the Flenniken laboratory (Katie Daughenbaugh, Ian Cavigli, Emma Garcia, Madison Martin, and Will Glenny) for reviewing this paper prior to publication.

\section{References}

[1] N. W. Calderone, "Insect pollinated crops, insect pollinators and US agriculture: trend analysis of aggregate data for the period 1992-2009," PLoS ONE, vol. 7, no. 5, Article ID e37235, 2012.

[2] G. V. Amdam, Z. L. P. Simões, K. R. Guidugli, K. Norberg, and S. W. Omholt, "Disruption of vitellogenin gene function in adult honeybees by intra-abdominal injection of doublestranded RNA," BMC Biotechnology, vol. 3, article 1, 2003.

[3] R. Kucharski, J. Maleszka, S. Foret, and R. Maleszka, "Nutritional control of reproductive status in honeybees via DNA methylation," Science, vol. 319, no. 5871, pp. 1827-1830, 2008.

[4] Y. Wang, N. S. Mutti, K. E. Ihle et al., "Down-regulation of honey bee IRS gene biases behavior toward food rich in protein," PLoS Genetics, vol. 6, no. 4, Article ID e1000896, 2010.

[5] H. Li-Byarlay, C. C. Rittschof, J. H. Massey, B. R. Pittendrigh, and G. E. Robinson, "Socially responsive effects of brain oxidative metabolism on aggression," Proceedings of the National Academy of Sciences of the United States of America, vol. 111, no. 34, pp. 12533-12537, 2014.

[6] D. A. Galbraith, X. Yang, E. L. Niño, S. Yi, C. Grozinger, and D. S. Schneider, "Parallel epigenomic and transcriptomic responses to viral infection in honey bees (Apis mellifera)," PLOS Pathogens, vol. 11, no. 3, Article ID e1004713, 2015.

[7] A. Zayed and G. E. Robinson, "Understanding the relationship between brain gene expression and social behavior: lessons from the honey bee," Annual Review of Genetics, vol. 46, pp. 591615, 2012.

[8] F. Nazzi and F. Pennacchio, "Disentangling multiple interactions in the hive ecosystem," Trends in Parasitology, vol. 30, no. 12, pp. 556-561, 2014.

[9] A. J. McMenamin and E. Genersch, "Honey bee colony losses and associated viruses," Current Opinion in Insect Science, vol. 8, pp. 121-129, 2015.

[10] L. M. Brutscher, K. F. Daughenbaugh, and M. L. Flenniken, "Antiviral defense mechanisms in honey bees," Current Opinion in Insect Science, vol. 10, pp. 71-82, 2015.
[11] R. van der Zee, L. Pisa, S. Andonov et al., "Managed honey bee colony losses in Canada, China, Europe, Israel and Turkey, for the winters of 2008-9 and 2009-10," Journal of Apicultural Research, vol. 51, no. 1, pp. 100-114, 2012.

[12] A. Clermont, M. Eickermann, F. Kraus, C. Georges, L. Hoffmann, and M. Beyer, "A survey on some factors potentially affecting losses of managed honey bee colonies in Luxembourg over the winters 2010/2011 and 2011/2012," Journal of Apicultural Research, vol. 53, no. 1, pp. 43-56, 2014.

[13] K. Lee, N. A. Steinhauer, K. Rennich et al., "A national survey of managed honey bee 2013-2014 annual colony losses in the USA: results from the Bee Informed Partnership," Apidologie, vol. 46, pp. 292-305, 2015.

[14] D. van Engelsdorp, J. Hayes Jr., R. M. Underwood, and J. Pettis, "A survey of honey bee colony losses in the U.S., fall 2007 to spring 2008," PLoS ONE, vol. 3, no. 12, Article ID e4071, 2008.

[15] D. vanEngelsdorp, J. D. Evans, C. Saegerman et al., "Colony collapse disorder: a descriptive study," PLoS ONE, vol. 4, no. 8, article e6481, 2009.

[16] D. vanEngelsdorp, D. Caron, J. Hayes et al., "A national survey of managed honey bee 2010-11 winter colony losses in the USA: results from the Bee Informed Partnership," Journal of Apicultural Research, vol. 51, no. 1, pp. 115-124, 2012.

[17] A. M. Spleen, E. J. Lengerich, K. Rennich et al., "A national survey of managed honey bee 2011-12 winter colony losses in the United States: results from the bee informed partnership," Journal of Apicultural Research, vol. 52, no. 2, pp. 44-53, 2013.

[18] N. A. Steinhauer, K. Rennich, M. E. Wilson et al., "A national survey of managed honey bee 2012-2013 annual colony losses in the USA: results from the Bee informed partnership," Journal of Apicultural Research, vol. 53, no. 1, pp. 1-18, 2014.

[19] D. L. Cox-Foster, S. Conlan, E. C. Holmes et al., "A metagenomic survey of microbes in honey bee colony collapse disorder," Science, vol. 318, no. 5848, pp. 283-287, 2007.

[20] R. S. Cornman, D. R. Tarpy, Y. Chen et al., "Pathogen webs in collapsing honey bee colonies," PLoS ONE, vol. 7, no. 8, Article ID e43562, 2012.

[21] Y. P. Chen, J. S. Pettis, M. Corona et al., "Israeli acute paralysis virus: epidemiology, pathogenesis and implications for honey bee health," PLoS Pathogens, vol. 10, no. 7, Article ID e1004261, 2014.

[22] K. Daughenbaugh, M. Martin, L. Brutscher et al., "Honey bee infecting Lake Sinai viruses," Viruses, vol. 7, no. 6, pp. 3285-3309, 2015.

[23] R. Van der Zee, L. Pisa, S. Andonov et al., "Managed honey bee colony losses in Canada, China, Europe, Israel and Turkey, for the winters of 2008-9 and 2009-10," Journal of Apicultural Research, vol. 51, no. 1, pp. 100-114, 2012.

[24] F. Granberg, M. Vicente-Rubiano, C. Rubio-Guerri et al., "Metagenomic detection of viral pathogens in Spanish honeybees: co-infection by Aphid Lethal Paralysis, Israel Acute Paralysis and Lake Sinai Viruses," PLoS ONE, vol. 8, no. 2, Article ID e57459, 2013.

[25] F. Nazzi, S. P. Brown, D. Annoscia et al., "Synergistic parasitepathogen interactions mediated by host immunity can drive the collapse of honeybee colonies," PLoS Pathogens, vol. 8, no. 6, Article ID e1002735, 2012.

[26] F. Mutinelli, C. Costa, M. Lodesani et al., "Honey bee colony losses in Italy," Journal of Apicultural Research, vol. 49, no. 1, pp. 119-120, 2010. 
[27] J. Ravoet, J. Maharramov, I. Meeus et al., "Comprehensive bee pathogen screening in Belgium reveals Crithidia mellificae as a new contributory factor to winter mortality," PLOS ONE, vol. 8, no. 8, Article ID e72443, 2013.

[28] E. Genersch, W. von der Ohe, H. Kaatz et al., "The German bee monitoring project: a long term study to understand periodically high winter losses of honey bee colonies," Apidologie, vol. 41, no. 3, pp. 332-352, 2010.

[29] Y. P. Chen, J. S. Pettis, M. Corona et al., "Israeli acute paralysis virus: epidemiology, pathogenesis and implications for honey bee health," PLoS Pathogens, vol. 10, no. 7, Article ID e1004261, 2014.

[30] I. Cavigli, K. F. Daughenbaugh, M. Martin et al., "Pathogen prevalence and abundance in honey bee colonies involved in almond pollination," Apidologie, pp. 1-16, 2015.

[31] J. D. Evans and R. S. Schwarz, "Bees brought to their knees: microbes affecting honey bee health," Trends in Microbiology, vol. 19, no. 12, pp. 614-620, 2011.

[32] S.-W. Ding, "RNA-based antiviral immunity," Nature Reviews Immunology, vol. 10, no. 9, pp. 632-644, 2010.

[33] S. M. Hammond, A. A. Caudy, and G. J. Hannon, "Post-transcriptional gene silencing by double-stranded RNA," Nature Reviews Genetics, vol. 2, no. 2, pp. 110-119, 2001.

[34] E. Maori, N. Paldi, S. Shafir et al., "IAPV, a bee-affecting virus associated with colony collapse disorder can be silenced by dsRNA ingestion," Insect Molecular Biology, vol. 18, no. 1, pp. 5560, 2009.

[35] W. Hunter, J. Ellis, D. Vanengelsdorp et al., "Large-scale field application of RNAi technology reducing Israeli acute paralysis virus disease in honey bees (Apis mellifera, hymenoptera: Apidae)," PLoS Pathogens, vol. 6, no. 12, Article ID e1001160, 2010.

[36] X. Liu, Y. Zhang, X. Yan, and R. Han, "Prevention of chinese sacbrood virus infection in apis cerana using rna interference," Current Microbiology, vol. 61, no. 5, pp. 422-428, 2010.

[37] S. D. Desai, Y.-J. Eu, S. Whyard, and R. W. Currie, "Reduction in deformed wing virus infection in larval and adult honey bees (Apis mellifera L.) by double-stranded RNA ingestion," Insect Molecular Biology, vol. 21, no. 4, pp. 446-455, 2012.

[38] M. L. Flenniken and R. Andino, "Non-specific dsRNAmediated antiviral response in the honey bee," PLOS ONE, vol. 8, no. 10, Article ID e77263, 2013.

[39] Y. E. Chen and J. D. Evans, "RNAi in treating honey bee diseases," Bee Culture, vol. 140, pp. 27-29, 2012.

[40] A. Jarosch and R. F. A. Moritz, "RNA interference in honeybees: off-target effects caused by dsRNA," Apidologie, vol. 43, no. 2, pp. 128-138, 2012.

[41] F. M. F. Nunes, A. C. Aleixo, A. R. Barchuk, A. D. Bomtorin, C. M. Grozinger, and Z. L. P. Simões, "Non-target effects of green fluorescent protein (GFP)-derived double-stranded RNA (dsRNA-GFP) used in honey bee RNA interference (RNAi) assays," Insects, vol. 4, no. 1, pp. 90-103, 2013.

[42] B. Goic, N. Vodovar, J. A. Mondotte et al., "RNA-mediated interference and reverse transcription control the persistence of RNA viruses in the insect model Drosophila," Nature Immunology, vol. 14, no. 4, pp. 396-403, 2013.

[43] G. J. Seo, R. P. Kincaid, T. Phanaksri et al., "Reciprocal inhibition between intracellular antiviral signaling and the RNAi machinery in mammalian cells," Cell Host and Microbe, vol. 14, no. 4, pp. 435-445, 2013.
[44] P. V. Maillard, C. Ciaudo, A. Marchais et al., "Antiviral RNA interference in mammalian cells," Science, vol. 342, no. 6155, pp. 235-238, 2013.

[45] S.-W. Ding and O. Voinnet, "Antiviral RNA silencing in mammals: no news is not good news," Cell Reports, vol. 9, no. 3, pp. 795-797, 2014.

[46] X.-H. Wang, R. Aliyari, W.-X. Li et al., "RNA interference directs innate immunity against viruses in adult Drosophila," Science, vol. 312, no. 5772, pp. 452-454, 2006.

[47] S. Deddouche, N. Matt, A. Budd et al., "The DExD/H-box helicase Dicer-2 mediates the induction of antiviral activity in drosophila," Nature Immunology, vol. 9, no. 12, pp. 1425-1432, 2008.

[48] G. M. Weinstock, G. E. Robinson, R. A. Gibbs et al., "Insights into social insects from the genome of the honeybee Apis mellifera," Nature, vol. 443, no. 7114, pp. 931-949, 2006.

[49] A. W. Bronkhorst and R. P. van Rij, "The long and short of antiviral defense: small RNA-based immunity in insects," Current Opinion in Virology, vol. 7, no. 1, pp. 19-28, 2014.

[50] R. C. Wilson and J. A. Doudna, "Molecular mechanisms of RNA interference," Annual Review of Biophysics, vol. 42, no. 1, pp. 217239, 2013.

[51] S. Asgari, "Regulatory role of cellular and viral microRNAs in insect-virus interactions," Current Opinion in Insect Science, vol. 8, pp. 104-110, 2015.

[52] J. Brennecke, A. A. Aravin, A. Stark et al., "Discrete small RNAgenerating loci as master regulators of transposon activity in Drosophila," Cell, vol. 128, no. 6, pp. 1089-1103, 2007.

[53] A. Nayak, M. Tassetto, M. Kunitomi, and R. Andino, "RNA interference-mediated intrinsic antiviral immunity in invertebrates," in Intrinsic Immunity, vol. 371 of Current Topics in Microbiology and Immunology, pp. 183-200, Springer, Berlin, Germany, 2013.

[54] M. Beye, S. Härtel, A. Hagen, M. Hasselmann, and S. W. Omholt, "Specific developmental gene silencing in the honey bee using a homeobox motif," Insect Molecular Biology, vol. 11, no. 6, pp. 527-532, 2002.

[55] M. Beye, M. Hasselmann, M. K. Fondrk, R. E. Page Jr., and S. W. Omholt, "The gene csd is the primary signal for sexual development in the honeybee and encodes an SR-type protein," Cell, vol. 114, no. 4, pp. 419-429, 2003.

[56] T. Gempe, M. Hasselmann, M. Schiøtt, G. Hause, M. Otte, and M. Beye, "Sex determination in honeybees: two separate mechanisms induce and maintain the female pathway," PLoS Biology, vol. 7, no. 10, Article ID e1000222, 2009.

[57] J. Maleszka, S. Forêt, R. Saint, and R. Maleszka, "RNAi-induced phenotypes suggest a novel role for a chemosensory protein CSP5 in the development of embryonic integument in the honeybee (Apis mellifera)," Development Genes and Evolution, vol. 217, no. 3, pp. 189-196, 2007.

[58] I. Nissen, M. Müller, and M. Beye, "The Am-tra2 gene is an essential regulator of female splice regulation at two levels of the sex determination hierarchy of the honeybee," Genetics, vol. 192, no. 3, pp. 1015-1026, 2012.

[59] M. J. Wilson and P. K. Dearden, "Tailless patterning functions are conserved in the honeybee even in the absence of Torso signaling," Developmental Biology, vol. 335, no. 1, pp. 276-287, 2009.

[60] M. J. Wilson, N. J. Kenny, and P. K. Dearden, "Components of the dorsal-ventral pathway also contribute to anterior-posterior patterning in honeybee embryos (Apis mellifera)," EvoDevo, vol. 5, article 11, 2014. 
[61] K. Aronstein and E. Saldivar, "Characterization of a honey bee Toll related receptor gene Am18w and its potential involvement in antimicrobial immune defense," Apidologie, vol. 36, no. 1, pp. 3-14, 2005.

[62] A. Patel, M. K. Fondrk, O. Kaftanoglu et al., "The making of a queen: TOR pathway is a key player in diphenic caste development," PLoS ONE, vol. 2, no. 6, article e509, 2007.

[63] M. Hasselmann, T. Gempe, M. Schiøtt, C. G. Nunes-Silva, M. Otte, and M. Beye, "Evidence for the evolutionary nascence of a novel sex determination pathway in honeybees," Nature, vol. 454, no. 7203, pp. 519-522, 2008.

[64] F. M. F. Nunes and Z. L. P. Simões, "A non-invasive method for silencing gene transcription in honeybees maintained under natural conditions," Insect Biochemistry and Molecular Biology, vol. 39, no. 2, pp. 157-160, 2009.

[65] M. Kamakura, "Royalactin induces queen differentiation in honeybees," Nature, vol. 473, no. 7348, pp. 478-483, 2011.

[66] N. S. Mutti, A. G. Dolezal, F. Wolschin, J. S. Mutti, K. S. Gill, and G. V. Amdam, "IRS and TOR nutrient-signaling pathways act via juvenile hormone to influence honey bee caste fate," Journal of Experimental Biology, vol. 214, no. 23, pp. 3977-3984, 2011.

[67] N. S. Mutti, Y. Wang, O. Kaftanoglu, and G. V. Amdam, "Honey bee PTEN_description, developmental knockdown, and tissue-specific expression of splice-variants correlated with alternative social phenotypes," PLoS ONE, vol. 6, no. 7, Article ID e22195, 2011.

[68] F. Wolschin, N. S. Mutti, and G. V. Amdam, "Insulin receptor substrate influences female caste development in honeybees," Biology Letters, vol. 7, no. 1, pp. 112-115, 2011.

[69] A. R. Barchuk, V. L. C. Figueiredo, and Z. L. P. Simões, "Downregulation of ultraspiracle gene expression delays pupal development in honeybees," Journal of Insect Physiology, vol. 54, no. 6, pp. 1035-1040, 2008.

[70] M. Elias-Neto, M. P. M. Soares, Z. L. P. Simões, K. Hartfelder, and M. M. G. Bitondi, "Developmental characterization, function and regulation of a Laccase 2 encoding gene in the honey bee, Apis mellifera (Hymenoptera, Apinae)," Insect Biochemistry and Molecular Biology, vol. 40, no. 3, pp. 241-251, 2010.

[71] T. Farooqui, H. Vaessin, and B. H. Smith, "Octopamine receptors in the honeybee (Apis mellifera) brain and their disruption by RNA-mediated interference," Journal of Insect Physiology, vol. 50, no. 8, pp. 701-713, 2004.

[72] K. R. Guidugli, A. M. Nascimento, G. V. Amdam et al., "Vitellogenin regulates hormonal dynamics in the worker caste of a eusocial insect," FEBS Letters, vol. 579, no. 22, pp. 49614965, 2005.

[73] S.-C. Seehuus, K. Norberg, U. Gimsa, T. Krekling, and G. V. Amdam, "Reproductive protein protects functionally sterile honey bee workers from oxidative stress," Proceedings of the National Academy of Sciences of the United States of America, vol. 103, no. 4, pp. 962-967, 2006.

[74] C. M. Nelson, K. E. Ihle, M. K. Fondrk, R. E. Page, and G. V. Amdam, "The gene vitellogenin has multiple coordinating effects on social organization," PLoS Biology, vol. 5, no. 3, article e62, 2007.

[75] A. Mackert, A. M. do Nascimento, M. M. G. Bitondi, K. Hartfelder, and Z. L. P. Simões, "Identification of a juvenile hormone esterase-like gene in the honey bee, Apis mellifera L.- expression analysis and functional assays," Comparative Biochemistry and Physiology Part B: Biochemistry and Molecular Biology, vol. 150, no. 1, pp. 33-44, 2008.
[76] D. S. Marco Antonio, K. R. Guidugli-Lazzarini, A. M. do Nascimento, Z. L. P. Simões, and K. Hartfelder, "RNAi-mediated silencing of vitellogenin gene function turns honeybee (Apis mellifera) workers into extremely precocious foragers," Naturwissenschaften, vol. 95, no. 10, pp. 953-961, 2008.

[77] J. A. Mustard, P. M. Pham, and B. H. Smith, "Modulation of motor behavior by dopamine and the D1-like dopamine receptor AmDOP2 in the honey bee," Journal of Insect Physiology, vol. 56, no. 4, pp. 422-430, 2010.

[78] A. Jarosch and R. F. A. Moritz, "Systemic RNA-interference in the honeybee Apis mellifera: tissue dependent uptake of fluorescent siRNA after intra-abdominal application observed by laser-scanning microscopy," Journal of Insect Physiology, vol. 57, no. 7, pp. 851-857, 2011.

[79] A. Jarosch, E. Stolle, R. M. Crewe, and R. F. A. Moritz, "Alternative splicing of a single transcription factor drives selfish reproductive behavior in honeybee workers (Apis mellifera)," Proceedings of the National Academy of Sciences of the United States of America, vol. 108, no. 37, pp. 15282-15287, 2011.

[80] K.-A. Nilsen, K. E. Ihle, K. Frederick et al., "Insulin-like peptide genes in honey bee fat body respond differently to manipulation of social behavioral physiology," Journal of Experimental Biology, vol. 214, part 9, pp. 1488-1497, 2011.

[81] Y. Wang, C. S. Brent, E. Fennern, and G. V. Amdam, “Gustatory perception and fat body energy metabolism are jointly affected by vitellogenin and juvenile hormone in honey bees," PLoS Genetics, vol. 8, no. 6, Article ID e1002779, 2012.

[82] G. Leboulle, C. Niggebrügge, R. Roessler, A. D. Briscoe, R. Menzel, and N. Hempel de Ibarra, "Characterisation of the RNA interference response against the long-wavelength receptor of the honeybee," Insect Biochemistry and Molecular Biology, vol. 43, no. 10, pp. 959-969, 2013.

[83] H. Li-Byarlay, Y. Li, H. Stroud et al., "RNA interference knockdown of DNA methyl-transferase 3 affects gene alternative splicing in the honey bee," Proceedings of the National Academy of Sciences of the United States of America, vol. 110, no. 31, pp. 12750-12755, 2013.

[84] J. Niu, I. Meeus, K. Cappelle, N. Piot, and G. Smagghe, “The immune response of the small interfering RNA pathway in the defense against bee viruses," Current Opinion in Insect Science, vol. 6, pp. 22-27, 2014.

[85] G. V. Amdam and S. W. Omholt, "The hive bee to forager transition in honeybee colonies: the double repressor hypothesis," Journal of Theoretical Biology, vol. 223, no. 4, pp. 451-464, 2003.

[86] E. L. Arrese and J. L. Soulages, "Insect fat body: energy, metabolism, and regulation," Annual Review of Entomology, vol. 55, pp. 207-225, 2010.

[87] H. S. Gatehouse, L. N. Gatehouse, L. A. Maloneb et al., "Amylase activity in honey bee hypopharyngeal glands reduced by RNA," Journal of Apicultural Research, vol. 43, no. 1, pp. 9-13, 2004.

[88] V. J. Marmaras and M. Lampropoulou, "Regulators and signalling in insect haemocyte immunity," Cellular Signalling, vol. 21, no. 2, pp. 186-195, 2009.

[89] M. B. Kingsolver and R. W. Hardy, "Making connections in insect innate immunity," Proceedings of the National Academy of Sciences of the United States of America, vol. 109, no. 46, pp. 18639-18640, 2012.

[90] M. B. Kingsolver, Z. Huang, and R. W. Hardy, "Insect antiviral innate immunity: pathways, effectors, and connections," Journal of Molecular Biology, vol. 425, no. 24, pp. 4921-4936, 2013. 
[91] C. G. Elsik, K. C. Worley, A. K. Bennett et al., "Finding the missing honey bee genes: lessons learned from a genome upgrade," BMC Genomics, vol. 15, article 86, 2014.

[92] Y. Chen, "Viruses and viral diseases of the honey bee, Apis mellifera," in Recent Advances in Entomological Research, T. Liu and L. Kang, Eds., pp. 105-120, Springer, 2011.

[93] J. R. de Miranda, L. Bailey, B. V. Ball et al., "Standard methods for virus research in Apis mellifera," Journal of Apicultural Research, vol. 52, no. 4, pp. 1-56, 2013.

[94] J. P. Burand and W. B. Hunter, "RNAi: future in insect management," Journal of Invertebrate Pathology, vol. 112, supplement 1 , pp. S68-S74, 2013.

[95] J. G. Scott, K. Michel, L. C. Bartholomay et al., "Towards the elements of successful insect RNAi," Journal of Insect Physiology, vol. 59, no. 12, pp. 1212-1221, 2013.

[96] N. Chejanovsky, R. Ophir, M. S. Schwager, Y. Slabezki, S. Grossman, and D. Cox-Foster, "Characterization of viral siRNA populations in honey bee colony collapse disorder," Virology, vol. 454-455, no. 1, pp. 176-183, 2014.

[97] E. V. Ryabov, G. R. Wood, J. M. Fannon et al., "A virulent strain of deformed wing virus (DWV) of honeybees (Apis mellifera) prevails after Varroa destructor-mediated, or in vitro, transmission," PLoS Pathogens, vol. 10, no. 6, Article ID e1004230, 2014.

[98] F. Zhu, H. Ding, and B. Zhu, "Transcriptional profiling of Drosophila S2 cells in early response to Drosophila C virus," Virology Journal, vol. 10, article 210, 2013.

[99] C. Dostert, E. Jouanguy, P. Irving et al., "The Jak-STAT signaling pathway is required but not sufficient for the antiviral response of drosophila," Nature Immunology, vol. 6, no. 9, pp. 946-953, 2005.

[100] A. Lingel, B. Simon, E. Izaurralde, and M. Sattler, “The structure of the flock house virus B2 protein, a viral suppressor of RNA interference, shows a novel mode of double-stranded RNA recognition," EMBO Reports, vol. 6, no. 12, pp. 1149-1155, 2005.

[101] J. A. Chao, H. L. June, B. R. Chapados, E. W. Debler, A. Schneemann, and J. R. Williamson, "Dual modes of RNAsilencing suppression by Flock House virus protein B2," Nature Structural \& Molecular Biology, vol. 12, no. 11, pp. 952-957, 2005.

[102] A. Nayak, B. Berry, M. Tassetto et al., "Cricket paralysis virus antagonizes Argonaute 2 to modulate antiviral defense in Drosophila," Nature Structural \& Molecular Biology, vol. 17, no. 5, pp. 547-554, 2010.

[103] R. P. van Rij, M.-C. Saleh, B. Berry et al., "The RNA silencing endonuclease Argonaute 2 mediates specific antiviral immunity in Drosophila melanogaster," Genes \& Development, vol. 20, no. 21, pp. 2985-2995, 2006.

[104] H. Huvenne and G. Smagghe, "Mechanisms of dsRNA uptake in insects and potential of RNAi for pest control: a review," Journal of Insect Physiology, vol. 56, no. 3, pp. 227-235, 2010.

[105] J. Ulvila, M. Parikka, A. Kleino et al., "Double-stranded RNA is internalized by scavenger receptor-mediated endocytosis in Drosophila S2 cells," The Journal of Biological Chemistry, vol. 281, no. 20, pp. 14370-14375, 2006.

[106] M.-C. Saleh, R. P. van Rij, A. Hekele et al., "The endocytic pathway mediates cell entry of dsRNA to induce RNAi silencing," Nature Cell Biology, vol. 8, no. 8, pp. 793-802, 2006.

[107] M.-C. Saleh, M. Tassetto, R. P. Van Rij et al., "Antiviral immunity in Drosophila requires systemic RNA interference spread," Nature, vol. 458, no. 7236, pp. 346-350, 2009.

[108] W. M. Winston, C. Molodowitch, and C. P. Hunter, "Systemic RNAi in C. elegans requires the putative transmembrane protein SID-1," Science, vol. 295, no. 5564, pp. 2456-2459, 2002.
[109] E. H. Feinberg and C. P. Hunter, "Transport of dsRNA into cells by the transmembrane protein SID-1," Science, vol. 301, no. 5639, pp. 1545-1547, 2003.

[110] K. Aronstein, T. Pankiw, and E. Saldivar, "SID-1 is implicated in systemic gene silencing in the honey bee," Journal of Apicultural Research, vol. 45, no. 1, pp. 20-24, 2006.

[111] A. Hinas, A. J. Wright, and C. P. Hunter, "SID-5 is an endosomeassociated protein required for efficient systemic RNAi in $C$. elegans," Current Biology, vol. 22, no. 20, pp. 1938-1943, 2012.

[112] A. M. Jose, Y. A. Kim, S. Leal-Ekman, and C. P. Hunter, "Conserved tyrosine kinase promotes the import of silencing RNA into Caenorhabditis elegans cells," Proceedings of the National Academy of Sciences of the United States of America, vol. 109, no. 36, pp. 14520-14525, 2012.

[113] D. L. McEwan, A. S. Weisman, and C. P. Hunter, "Uptake of extracellular double-stranded RNA by SID-2," Molecular Cell, vol. 47, no. 5, pp. 746-754, 2012.

[114] C. Camacho, G. Coulouris, V. Avagyan et al., "BLAST+: architecture and applications," BMC Bioinformatics, vol. 10, article 421, 2009.

[115] N. Vodovar and M.-C. Saleh, "Of insects and viruses: the role of small RNAs in insect defence," in Advances in Insect Physiology, vol. 42, pp. 1-36, 2012.

[116] Y. Luo, X. Wang, D. Yu, and L. Kang, “The SID-1 doublestranded RNA transporter is not required for systemic RNAi in the migratory locust," RNA Biology, vol. 9, no. 5, pp. 663-671, 2012.

[117] N. Paldi, E. Glick, M. Oliva et al., "Effective gene silencing in a microsporidian parasite associated with honeybee (Apis mellifera) colony declines," Applied and Environmental Microbiology, vol. 76, no. 17, pp. 5960-5964, 2010.

[118] Y. Garbian, E. Maori, H. Kalev, S. Shafir, and I. Sela, "Bidirectional transfer of RNAi between honey bee and Varroa destructor: Varroa gene silencing reduces Varroa population," PLoS Pathogens, vol. 8, no. 12, Article ID e1003035, 2012.

[119] P. V. Ramachandran and S. Ignacimuthu, "RNA interferencea silent but an efficient therapeutic tool," Applied Biochemistry and Biotechnology, vol. 169, no. 6, pp. 1774-1789, 2013.

[120] D. L. Lewis, J. E. Hagstrom, A. G. Loomis, J. A. Wolff, and H. Herweijer, "Efficient delivery of siRNA for inhibition of gene expression in postnatal mice," Nature Genetics, vol. 32, no. 1, pp. 107-108, 2002.

[121] L. Han, C. Tang, and C. Yin, "Oral delivery of shRNA and siRNA via multifunctional polymeric nanoparticles for synergistic cancer therapy," Biomaterials, vol. 35, no. 15, pp. 4589-4600, 2014.

[122] E. Maori, E. Tanne, and I. Sela, "Reciprocal sequence exchange between non-retro viruses and hosts leading to the appearance of new host phenotypes," Virology, vol. 362, no. 2, pp. 342-349, 2007.

[123] S. H. Merkling and R. P. van Rij, "Beyond RNAi: antiviral defense strategies in Drosophila and mosquito," Journal of Insect Physiology, vol. 59, no. 2, pp. 159-170, 2013.

[124] S. Jensen and A. R. Thomsen, "Sensing of RNA viruses: a review of innate immune receptors involved in recognizing RNA virus invasion," Journal of Virology, vol. 86, no. 6, pp. 2900-2910, 2012.

[125] P. C. Ronald and B. Beutler, "Plant and animal sensors of conserved microbial signatures," Science, vol. 330, no. 6007, pp. 1061-1064, 2010.

[126] J. D. Evans, K. Aronstein, Y. P. Chen et al., "Immune pathways and defence mechanisms in honey bees Apis mellifera," Insect Molecular Biology, vol. 15, no. 5, pp. 645-656, 2006. 
[127] N. Piot, S. Snoeck, M. Vanlede, G. Smagghe, and I. Meeus, “The effect of oral administration of dsRNA on viral replication and mortality in bombus terrestris," Viruses, vol. 7, no. 6, pp. 31723185, 2015.

[128] J. W. Schoggins and C. M. Rice, "Interferon-stimulated genes and their antiviral effector functions," Current Opinion in Virology, vol. 1, no. 6, pp. 519-525, 2011.

[129] M. Hirai, O. Terenius, W. Li, and I. Faye, "Baculovirus and dsRNA induce Hemolin, but no antibacterial activity, in Antheraea pernyi," Insect Molecular Biology, vol. 13, no. 4, pp. 399-405, 2004.

[130] J. Robalino, C. L. Browdy, S. Prior et al., "Induction of antiviral immunity by double-stranded RNA in a marine invertebrate," Journal of Virology, vol. 78, no. 19, pp. 10442-10448, 2004.

[131] J. Robalino, T. C. Bartlett, R. W. Chapman, P. S. Gross, C. L. Browdy, and G. W. Warr, "Double-stranded RNA and antiviral immunity in marine shrimp: inducible host mechanisms and evidence for the evolution of viral counter-responses," Developmental \& Comparative Immunology, vol. 31, no. 6, pp. 539-547, 2007.

[132] Y. Labreuche, A. Veloso, E. de la Vega et al., "Non-specific activation of antiviral immunity and induction of RNA interference may engage the same pathway in the Pacific white leg shrimp Litopenaeus vannamei," Developmental and Comparative Immunology, vol. 34, no. 11, pp. 1209-1218, 2010.

[133] P. Attasart, R. Kaewkhaw, C. Chimwai, U. Kongphom, O. Namramoon, and S. Panyim, "Inhibition of Penaeus monodon densovirus replication in shrimp by double-stranded RNA," Archives of Virology, vol. 155, no. 6, pp. 825-832, 2010.

[134] L. C. Bartholomay, D. S. Loy, J. Dustin Loy, and D. L. Harris, "Nucleic-acid based antivirals: augmenting RNA interference to 'vaccinate' Litopenaeus vannamei," Journal of Invertebrate Pathology, vol. 110, no. 2, pp. 261-266, 2012.

[135] J. Liu, G. Smagghe, and L. Swevers, “Transcriptional response of BmToll9-1 and RNAi machinery genes to exogenous dsRNA in the midgut of Bombyx mori," Journal of Insect Physiology, vol. 59, no. 6, pp. 646-654, 2013.

[136] A. N. Pitaluga, P. W. Mason, and Y. M. Traub-Cseko, "Nonspecific antiviral response detected in RNA-treated cultured cells of the sandfly, Lutzomyia longipalpis," Developmental \& Comparative Immunology, vol. 32, no. 3, pp. 191-197, 2008.

[137] P. N. Paradkar, L. Trinidad, R. Voysey, J.-B. Duchemin, and P. J. Walker, "Secreted Vago restricts West Nile virus infection in Culex mosquito cells by activating the Jak-STAT pathway," Proceedings of the National Academy of Sciences of the United States of America, vol. 109, no. 46, pp. 18915-18920, 2012.

[138] D. R. Tarpy and T. D. Seeley, "Lower disease infections in honeybee (Apis mellifera) colonies headed by polyandrous vs monandrous queens," Naturwissenschaften, vol. 93, no. 4, pp. 195-199, 2006.

[139] D. R. Tarpy, D. Vanengelsdorp, and J. S. Pettis, "Genetic diversity affects colony survivorship in commercial honey bee colonies," Naturwissenschaften, vol. 100, no. 8, pp. 723-728, 2013.

[140] C. Runckel, M. L. Flenniken, J. C. Engel et al., "Temporal analysis of the honey bee microbiome reveals four novel viruses and seasonal prevalence of known viruses, Nosema, and Crithidia," PLoS ONE, vol. 6, no. 6, Article ID e20656, 2011.

[141] M. M. Wheeler and G. E. Robinson, "Diet-dependent gene expression in honey bees: honey vs. sucrose or high fructose corn syrup," Scientific Reports, vol. 4, article 5726, 2014.

[142] G. DeGrandi-Hoffman, Y. Chen, E. Huang, and M. H. Huang, "The effect of diet on protein concentration, hypopharyngeal gland development and virus load in worker honey bees (Apis mellifera L.)," Journal of Insect Physiology, vol. 56, no. 9, pp. 11841191, 2010.

[143] G. Di Pasquale, M. Salignon, Y. Le Conte et al., "Influence of pollen nutrition on honey bee health: do pollen quality and diversity matter?" PLoS ONE, vol. 8, no. 8, Article ID e72016, 2013.

[144] N. A. Moran, A. K. Hansen, J. E. Powell, and Z. L. Sabree, "Distinctive gut microbiota of honey bees assessed using deep sampling from individual worker bees," PLoS ONE, vol. 7, no. 4, Article ID e36393, 2012.

[145] H. R. Mattila, D. Rios, V. E. Walker-Sperling, G. Roeselers, and I. L. G. Newton, "Characterization of the active microbiotas associated with honey bees reveals healthier and broader communities when colonies are genetically diverse," PLoS ONE, vol. 7, no. 3, Article ID e32962, 2012.

[146] J. S. Pettis, D. vanEngelsdorp, J. Johnson, and G. Dively, "Pesticide exposure in honey bees results in increased levels of the gut pathogen Nosema," Naturwissenschaften, vol. 99, no. 2, pp. 153-158, 2012.

[147] G. Di Prisco, V. Cavaliere, D. Annoscia et al., "Neonicotinoid clothianidin adversely affects insect immunity and promotes replication of a viral pathogen in honey bees," Proceedings of the National Academy of Sciences of the United States of America, vol. 110, no. 46, pp. 18466-18471, 2013.

[148] V. Doublet, M. Labarussias, J. R. de Miranda, R. F. A. Moritz, and R. J. Paxton, "Bees under stress: Sublethal doses of a neonicotinoid pesticide and pathogens interact to elevate honey bee mortality across the life cycle," Environmental Microbiology, vol. 17, no. 4, pp. 969-983, 2015.

[149] H. Boncristiani, R. Underwood, R. Schwarz, J. D. Evans, J. Pettis, and D. vanEngelsdorp, "Direct effect of acaricides on pathogen loads and gene expression levels in honey bees Apis mellifera," Journal of Insect Physiology, vol. 58, no. 5, pp. 613-620, 2012.

[150] M. Bergem, K. Norberg, and R. M. Aamodt, "Long-term maintenance of in vitro cultured honeybee (Apis mellifera) embryonic cells," BMC Developmental Biology, vol. 6, article 17, 2006.

[151] G. S. Barbara, B. Grünewald, S. Paute, M. Gauthier, and V. Raymond-Delpech, "Study of nicotinic acetylcholine receptors on cultured antennal lobe neurones from adult honeybee brains," Invertebrate Neuroscience, vol. 8, no. 1, pp. 19-29, 2008.

[152] B. Grünewald and A. Wersing, "An ionotropic GABA receptor in cultured mushroom body Kenyon cells of the honeybee and its modulation by intracellular calcium," Journal of Comparative Physiology A: Neuroethology, Sensory, Neural, and Behavioral Physiology, vol. 194, no. 4, pp. 329-340, 2008.

[153] M. J. Goblirsch, M. S. Spivak, and T. J. Kurtti, "A cell line resource derived from honey bee (Apis mellifera) embryonic tissues," PLoS ONE, vol. 8, no. 7, Article ID e69831, 2013.

[154] E. Pennisi, “The CRISPR craze," Science, vol. 341, no. 6148, pp. 833-836, 2013. 


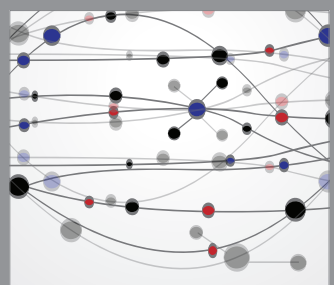

The Scientific World Journal
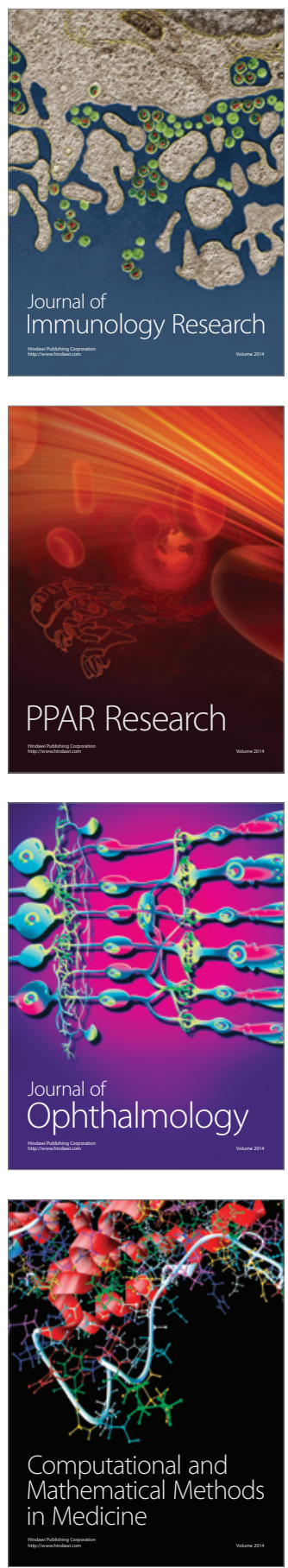

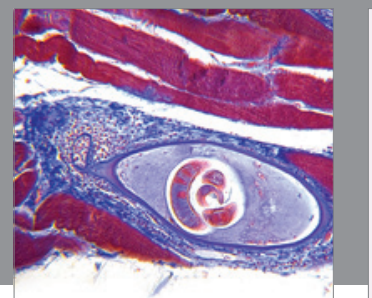

Gastroenterology

Research and Practice
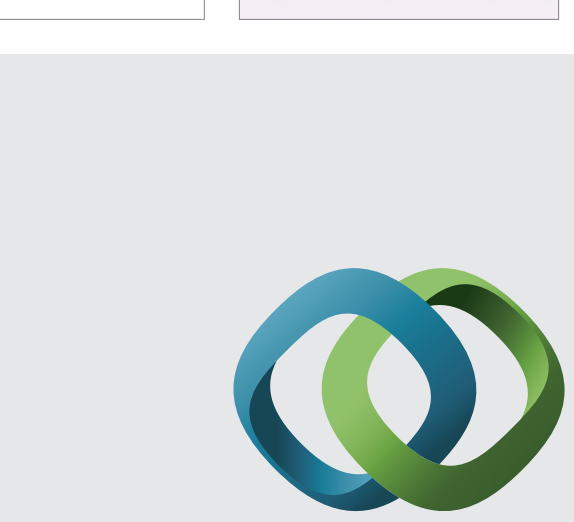

\section{Hindawi}

Submit your manuscripts at

http://www.hindawi.com
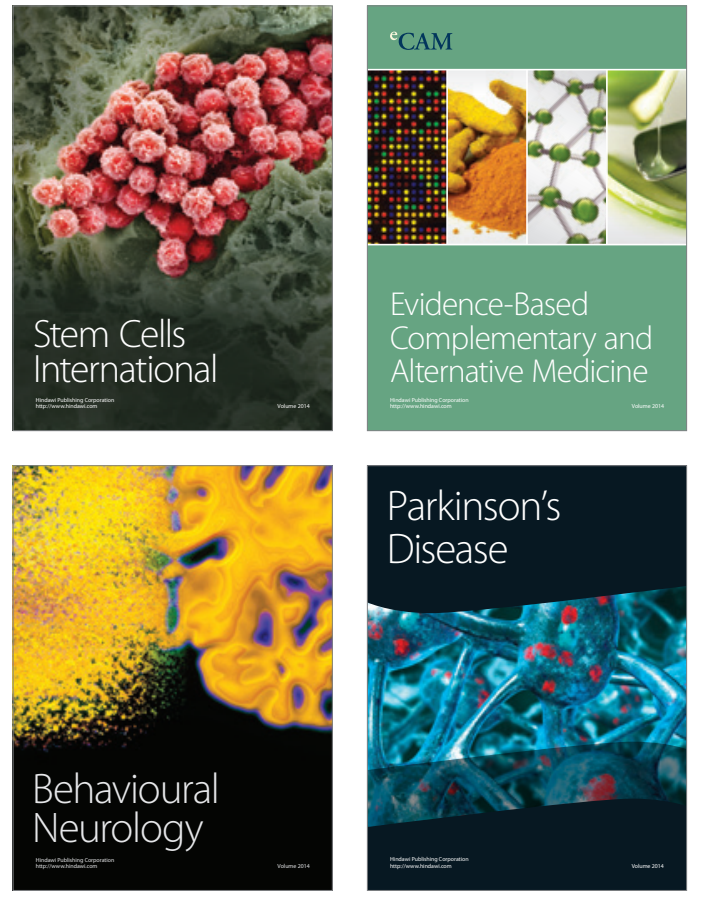
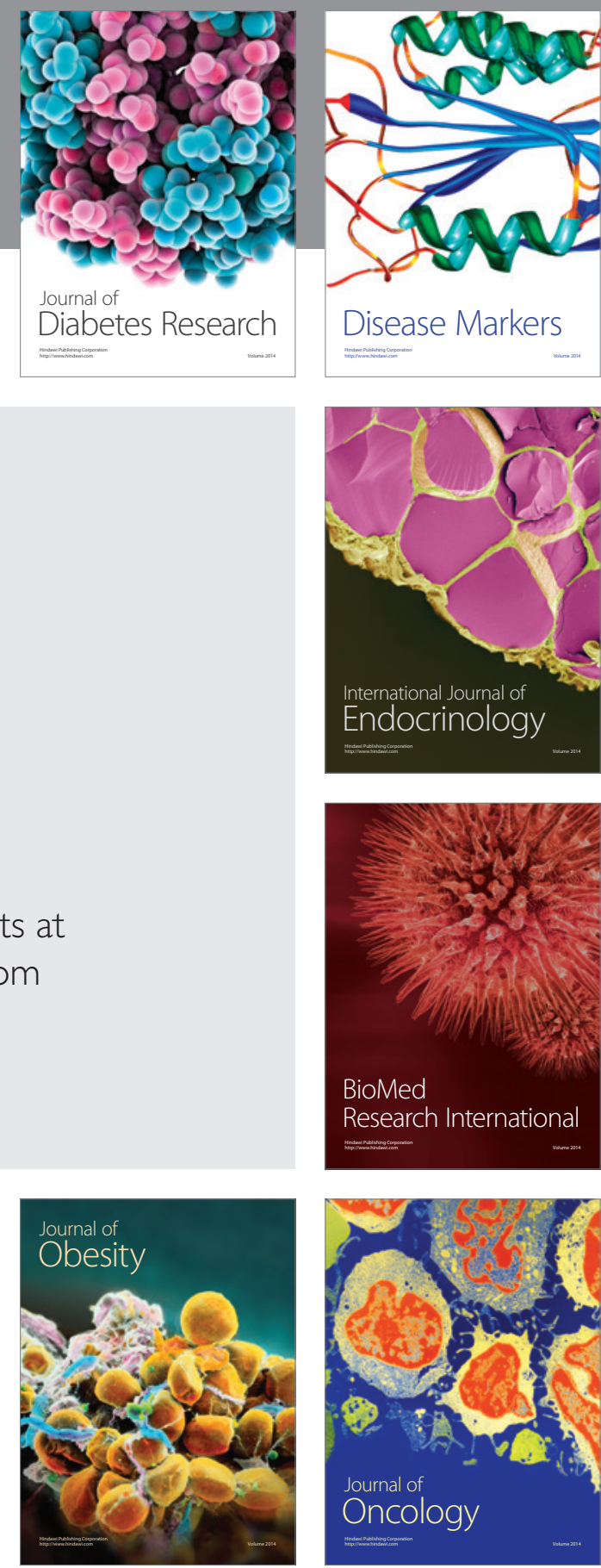

Disease Markers
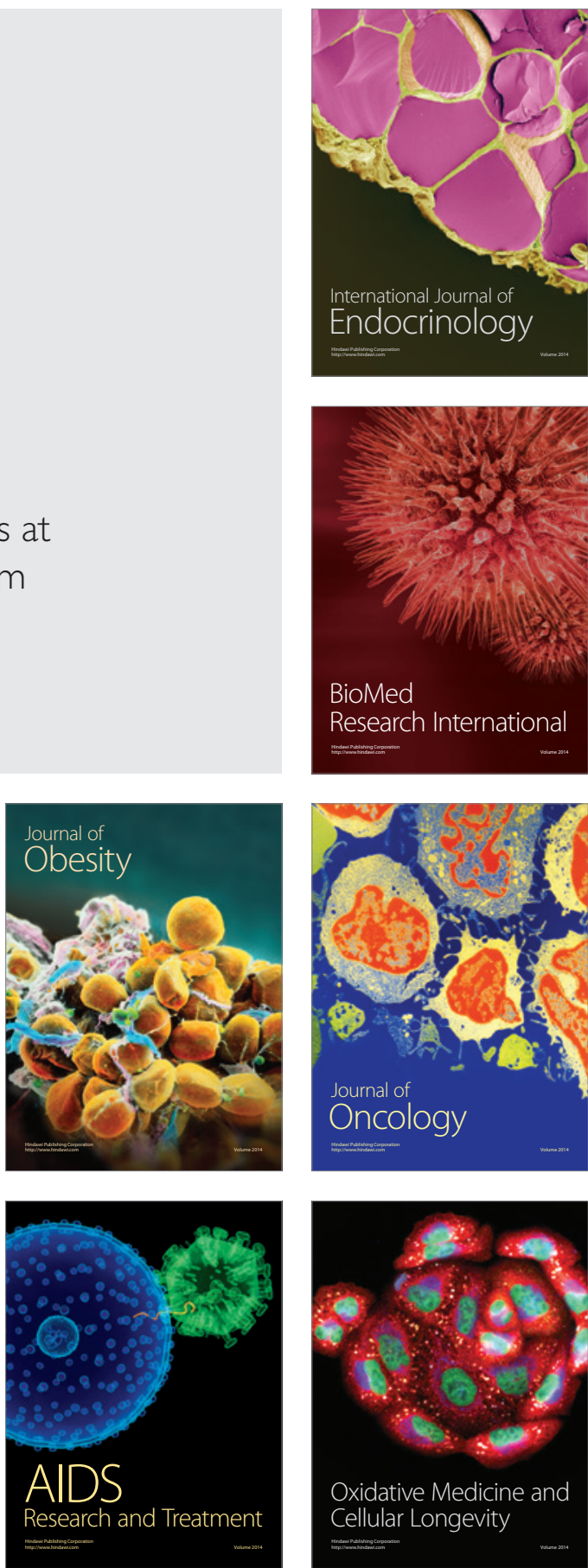